\title{
ОТДАЛЕННЫЕ РЕЗУЛЬТАТЫ ХИРУРГИЧЕСКОГО ЛЕЧЕНИЯ ЯЗВЕННОЙ БОЛЕЗНИ ЖЕЛУДКА И ДВЕНАДЦАТИПЕРСТНОЙ КИШКИ, ОСЛОЖНЕННОЙ ПЕРФОРАЦИЕЙ
}

\author{
(С) Суковатых Б.С. ${ }^{1}$, Гуреев И.И., Новомлинец Ю.П. ${ }^{1}$, Григорьев Н.Н. ${ }^{2}$ \\ ${ }^{1}$ Кафедра общей хирургии, ${ }^{2}$ кафедра хирургических болезней ФПО \\ Курского государственного медицинского университета, Курск \\ E-mail: igureev@inbox.ru
}

\begin{abstract}
Цель исследования - изучить влияние различных способов хирургического лечения язвенной болезни желудка и двенадцатиперстной кишки, осложненной перфорацией, на качество жизни пациентов Проведен сравнительный анализ влияния различных способов хирургического лечения у 118 больных перфоративной язвы на качество жизни. Больные были разделены на 4 группы: в первой группе выполнялось иссечение язвы, во второй - ушивание, в третьей - резекция желудка по модификации Бильрот-I, а в четвертой - по Бильрот-II. Наилучшим качеством жизни обладают больные, перенесшие иссечение язвы. На втором месте по влиянию на качество жизни находится резекция желудка по модификации Бильрот-I. Наихудшие отдаленные результаты получены при ушивании язвы и резекции желудка по модификации Бильрот-II.
\end{abstract}

Ключевые слова: язвенная болезнь, перфоративная язва, хирургическое лечение, иссечение, ушивание, резекция желудка, качество жизни.

\section{LONG-TERM RESULTS OF SURGICAL TREATMENT OF PEPTIC ULCER DISEASE COMPLICATED BY PERFORATION \\ Sukovatykh B.S., Gureev I.I., Novomlinets Yu.P., Grigoriev N.N. \\ ${ }^{1}$ Department of General Surgery, ${ }^{2}$ Department of Surgical Diseases of FPE of Kursk State Medical University, Kursk}

The aim of the study was to investigate the effect of various methods of surgical treatment of peptic ulcer complicated by perforation on the quality of life. A comparative analysis of the influence of different surgical treatment in 118 patients with a perforated ulcer on the quality of life was carried out. Patients were divided into 4 groups: in the first group, ulcer excision was performed, in the second one - suturing, in the third one - stomach resection according to a modification of Billroth I, and in the fourth one - according to Billroth II. The best quality of life is enjoyed by patients who have undergone ulcer excision. The Billroth I stomach resection ranks second with respect to the influence on the life quality. The worst long-term results are obtained by suturing an ulcer and the Billroth II gastric resection.

Keywords: peptic ulcer, perforated ulcer, surgical treatment, excision, suturing, gastric resection, quality of life.

Актуальность проблемы лечения язвенной болезни желудка и двенадцатиперстной кишки определяется тем, что она является основной причиной инвалидности $68 \%$ мужчин, 30,9\% женщин от числа всех страдающих заболеваниями органов пищеварения [4]. Несмотря на успехи в диагностике и лечении язвенной болезни, это заболевание продолжает поражать все более молодое население, не обнаруживая тенденций к стабилизации или снижению показателей заболеваемости [5,8].

Известно, что течение язвенной болезни осложняется перфорацией или кровотечением у 3-30\% больных [3]. При этом весьма существенной (до 25-50\%) становится доля больных, у которых перфорация и кровотечение сочетаются друг другом и (или) со стенозом пилоробульбарной зоны [1]. Предметом дискуссии является выбор способа хирургического лечения перфоративной язвы. В настоящее время применяются 3 основных способа хирургического лечения: ушивание перфоративного отверстия, иссечение перфоративной язвы, резекция желудка в модификации Бильрот-I или Бильрот-II. Анализ литературных данных показывает стремление хирургов минимизировать травматизм операции путем применения технологии лапароскопического ушивания перфоративной язвы $[6,7]$. Однако эта технология имеет и отрицательные стороны. Вопервых, лапароскопическое ушивание перфоративной язвы возможно лишь при отсутствии распространенного гнойного перитонита, требующего проведения тщательной санации брюшной полости и назоинтестинальной интубации тонкого кишечника. Во-вторых, простое ушивание перфоративного отверстия не избавляет пациента от язвенной болезни. Во всех областях хирургии оценка результатов лечения проводится на основании изучения качества жизни больных. Чем выше качество, тем лучше результат. Поэтому целесообразно изучить влияние различных способов хирургического лечения перфоративной язвы на качество жизни больных и на этой основе определить оптимальный метод лечения. 
Цель исследования - изучить влияние различных способов хирургического лечения язвенной болезни желудка и двенадцатиперстной кишки, осложненной перфорацией, на качество жизни пациентов.

\section{МАТЕРИАЛЫ И МЕТОДЫ ИССЛЕДОВАНИЯ}

Проведено изучение качества жизни у 118 пациентов, которым в течение 2012-2016 гг. в ОБУЗ ГКБ СМП г. Курска проводили хирургическое лечение язвенной болезни желудка и двенадцатиперстной кишки (ДПК), осложненной перфорацией. Всем больным перед оперативными вмешательствами была проведена стандартная диагностическая программа, которая включала клинические, лабораторные, рентгенологические, эндоскопические, ультразвуковые методы исследования. Больные были разделены на четыре группы по способам лечения перфоративной язвы. Первая состояла из $52(44,1 \%)$, которым было проведено иссечение язвы, вторая - из 19 (16,1\%), которым выполнено ушивание язвы, третья - из $34(28,8 \%)$, которым была проведена резекция 2/3 желудка по Бильрот-I, четвертая - из 13 (11\%) больных, которым выполнена резекция $2 / 3$ желудка по Бильрот-II в модификациях Витебского и Бальфура.
В первой группе иссечение язвы проводилось по оригинальной технологии с помощью, разработанного в нашей клинике комбинированного зажима (Пат. РФ на изобретение 91277 от 10.02.2010).

Комбинированный зажим состоит из двух губок жесткой фиксации (1), двух губок эластичной фиксации (2), узла движения (3) в виде глухого замка, браншей (4) для обеспечения подвижности фиксирующих и эластичных губок и зажима фиксации браншей в виде кремальеры (5). По наружной поверхности фиксирующих губок (1), параллельно и на расстоянии 4 мм от них располагаются губки эластичной фиксации (2), дистальные концы эластичных губок изогнуты в месте фиксации под радиус 4 мм. Бранши зажима изогнуты относительно фиксирующих губок под углом $145^{\circ}$ (рис. 1 ).

Способ представлен на примере закрытого иссечения прободной язвы малой кривизны желудка и осуществляется следующим образом. После лапаротомии производят мобилизацию участка малой кривизны желудка на протяжении 2 см проксимальнее и дистальнее язвенного инфильтрата. Стенку желудка с язвой прошивают лигатурой-держалкой. Вокруг язвенного инфильтрата малую кривизну желудка прошивают кисетным швом. Шов затягивают и завязывают, уменьшая диаметр основания удаляемого фрагмента (рис. 2).

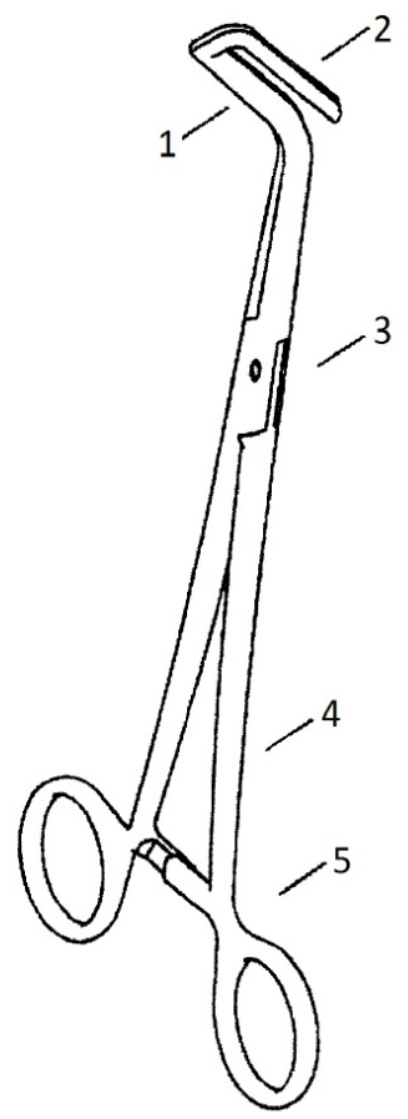

Рис. 1. Комбинированный зажим. 


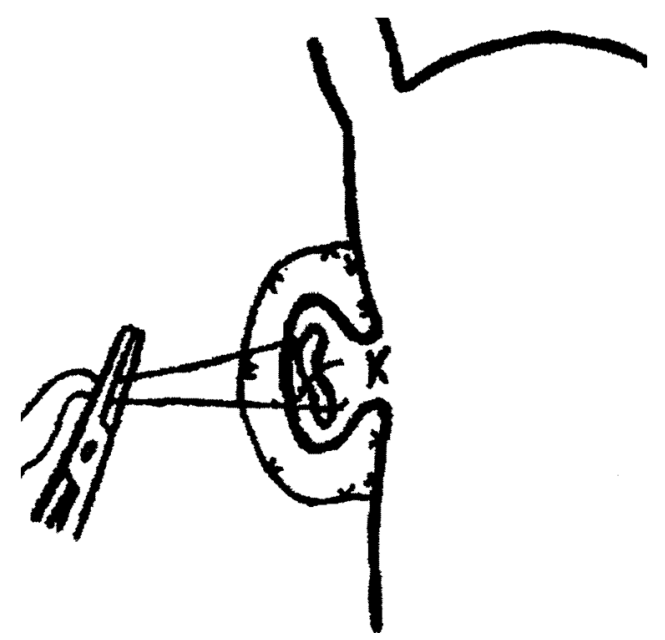

Рис. 2. Наложение кисетного шва вокруг язвы.

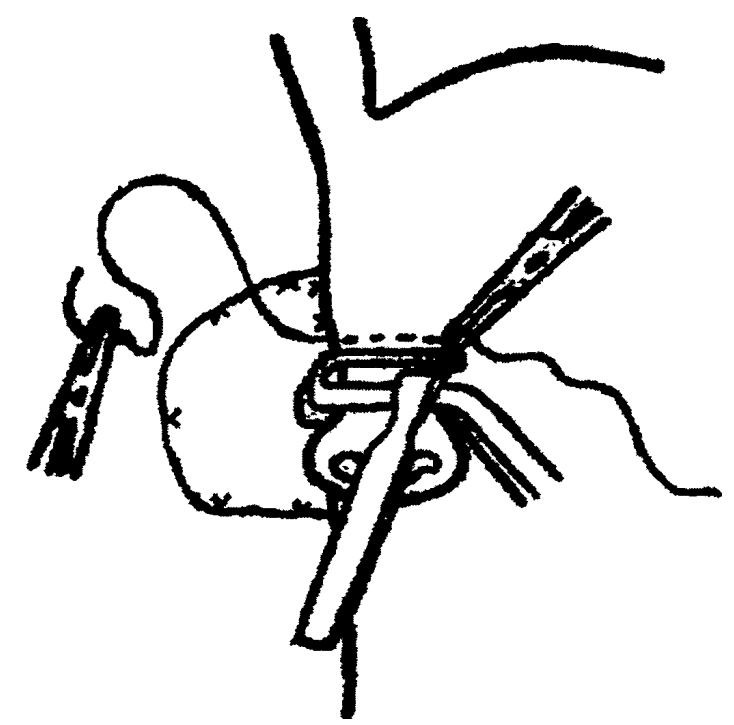

Рис. 4. Пересечение стенок фрагмента малой кривизны.

В поперечном направлении к малой кривизне желудка на основание фрагмента накладывают комбинированный зажим губками эластичной фиксации в сторону желудка. Зажим с фрагментом малой кривизны ротируют на $45^{\circ}$ и выводят из окна в малом сальнике на переднюю стенку желудка (рис. 3). Под губками эластичной фиксации основание фрагмента прошивают от передней поверхности к задней непрерывным трапециевидным швом, фиксируют концы лигатуры в натянутом положении. Между губками жесткой и эластичной фиксации зажима скальпелем пересекают стенки фрагмента малой кривизны и удаляют его вместе с зажимом (рис. 4). Продолжают выполнять второй этап двухэтажного непрерывного шва в виде обвивного прошивного от задней к передней стенке желудка, с затягиванием каждого стежка до достижения окончательного гемостаза. Начало и конец лигатур связывают (рис. 5). После обработки антисептиком линии прошивно-

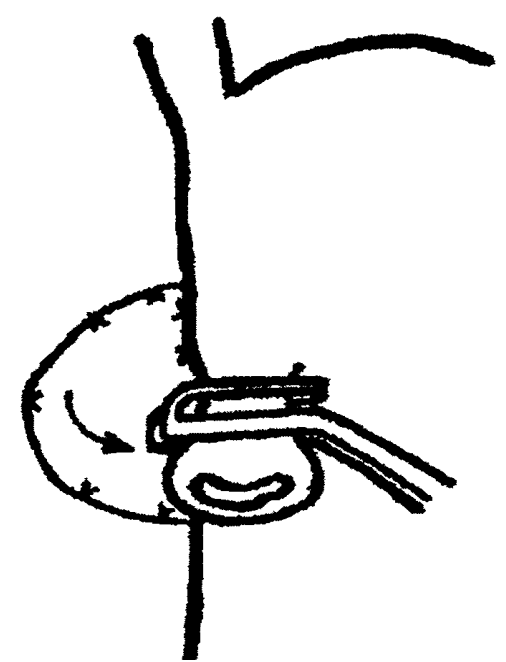

Рис. 3. Наложение комбинированного зажима.

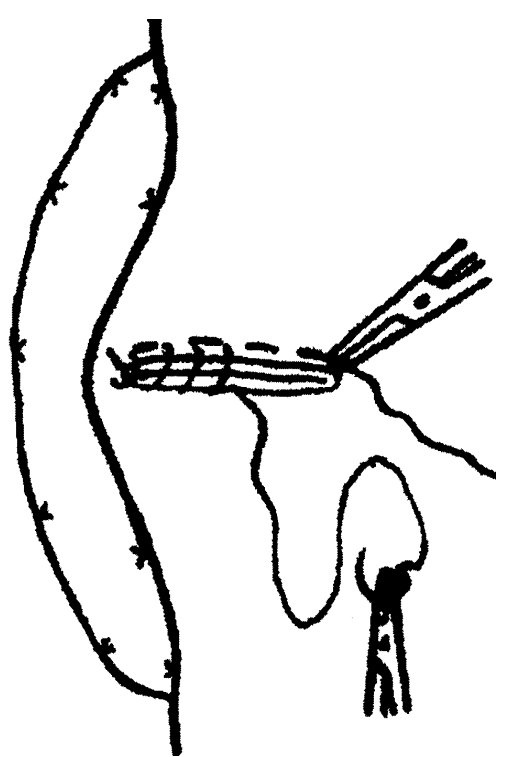

Рис. 5. Выполнение второго этапа двухэтажного непрерывного шва.

го шва, его перетонизируют узловыми серозномышечными швами.

Во второй группе ушивание язвы проводилось традиционным способом двухрядным швом. Техника резекций желудка по Бильрот-I в третьей группе и по Бильрот-II в четвертой группе также была традиционной.

Для оценки качества жизни был использован опросник "SF-36 Health Status Survey". SF-36 состоит из 36 вопросов, сгруппированных в восемь шкал: физическое функционирование (ФФ), физическая роль (ФР), физическая боль (ФБ), общая оценка здоровья (ООЗ), жизненная активность (ЖА), социальное функционирование (СФ), эмоциональная роль (ЭР) и психическое здоровье (П3). Показатели каждой шкалы составлены таким образом, что чем выше значение показателя (от 0 до 100), тем лучше оценка по избранной шкале. Из них формировали два интегральных параметра: физический компонент здоровья 
(ФКЗ) и психологический компонент здоровья (ПКЗ).

Для оценки эффективности проведенного хирургического лечения использовалась модифицированная шкала Visick [1]. Шкала была предложена автором в 1948 году для ранжирования вероятных состояний после резекции желудка и гастрэктомии по 5 уровням. В основу были положены клинические проявления болезней оперированного желудка и их влияние на повседневную жизнь пациента в качестве показателя общего благополучия.

Результаты хирургического лечения оценивались по следующим критериям:

Visick I (0-2 балла) (отличный результат) жалоб нет, отсутствие симптомов заболевания и негативных последствий операции, больной периодически принимает антисекреторные препараты с профилактической целью.

Visick II (3-6 баллов) (хороший результат) пациент считает себя здоровым, но периодически возникают незначительные боли в эпигастрии, непостоянные диспептические расстройства, легко устраняемые изменениями в режиме питания или приемом лекарственных средств.

Visick III (7-13 баллов) (удовлетворительный результат) - больной периодически отмечает сильные боли в животе или диспептические расстройства. Язвенная болезнь рецидивирует ежегодно при несоблюдении режима питания или рекомендаций врача. Консервативное лечение эффективно. После стационарного лечения ремиссия до 3 лет. Работоспособность не нарушена. Больной и хирург удовлетворены результатом операции.

Visick IV (14 баллов и более) (неудовлетворительный результат) - постоянные рецидивы язвенной болезни, плохо поддающиеся консервативному лечению, частые и выраженные болевые приступы, нарушается трудоспособность. Были повторные операции по поводу язвенной болезни или пациент нуждается в повторной операции. Хирург и больной не удовлетворены результатом лечения.

Статистическая обработка материала проводилась с использованием методов однофакторного дисперсного и корреляционного анализа. Вычисляли средние величины количественных показателей, стандартные ошибки и критерий согласия Пирсона $\left(\mathrm{x}^{2}\right)$. Полученные данные представлены в виде $\mathrm{M} \pm \mathrm{m}$. Существенность различия средних величин оценивали с помощью t-критерия Стьюдента. Различия считали статистически достоверными при $\mathrm{p}<0,05$.

\section{РЕЗУЛЬТАТЫ ИССЛЕДОВАНИЯ И ИХ ОБСУЖДЕНИЕ}

Сравнительная характеристика групп больных представлена в таблице 1 .

Перфоративные язвы двенадцатиперстной кишки встречались у 67 (56,8\%), а желудка у 51 (43,2\%). Больных молодого возраста по классификации ВОЗ до 45 лет было 71 (60,2\%), среднего возраста от 45 до 60 лет - 36 (30,5\%), пожилого возраста от 60 до 75 лет - 10 (8,5\%), старческого возраста свыше 75 лет - $1(0,8 \%)$. Лиц мужского пола было $106 \quad(89,8 \%)$, женского $12(10,2 \%)$. До 6 часов с момента перфорации поступило 68 (57,6\%), от 6 до 12 часов 27 (22,9\%), от 12 до 24 часов $21(17,8 \%)$, свыше 24 часов 2 (1,7\%) больных. 41 (34,7\%) больной страдал сопутствующим заболеванием внутренних органов, из которых на первом месте находятся ИБС, на втором - гипертоническая болезнь, на третьем - артроз крупных суставов и сахарный диабет. Во время операции серозный перитонит обнаружен у 48 (40,7\%), серозно-фибринозный - у 68 (57,6\%), гнойный - у 2 (1,7\%) больных. Местный перитонит выявлен у $49(41,5 \%)$, диффузный - у $27(22,9 \%)$ и распространенный - у $42(35,6 \%)$ пациентов.

Выбор метода хирургического лечения осуществляли следующим образом. При наличии хронической язвы с выраженным воспалительным валом производили ее иссечение по разработанному нами способу. Ушивание выполняли у больных при наличии острой язвы без воспалительного инфильтрата, ассоциированного с приемом лекарственных препаратов и в редких случаях при наличии распространенного гнойного перитонита, когда имеется большая вероятность несостоятельности швов после иссечения язвы. Резекцию желудка в модификации Бильрот-I и Бильрот-II производили при сочетании перфорации с другими осложнениями язвенной болезни (пенетрация, стеноз, кровотечение). Выбор способа резекции зависел от анатомических особенностей в области перфорации язвы. Если воспалительный инфильтрат ограничивался пилороантральной областью желудка и не распространялся дистальнее луковицы двенадцатиперстной кишки, производили резекцию желудка в модификации Бильрот-I. При выраженных воспалительных изменениях пилороантральной области желудка и двенадцатиперстной кишки выполняли резекцию по методике Бильрот-II. В ближайшем послеоперационном периоде при выполнении операций не было зарегистрировано технических ошибок и связанных с ними осложнений в анализируемых группах. Ни у одного больного не развилась несостоятельность швов после иссечения язвы по разработанному нами способу. 
Сравнительная характеристика больных в опытных группах

\begin{tabular}{|c|c|c|c|c|c|c|c|c|}
\hline \multirow{2}{*}{ Характеристика пациентов } & \multicolumn{2}{|c|}{$\begin{array}{c}1 \text { группа } \\
(\mathrm{n}=52)\end{array}$} & \multicolumn{2}{|c|}{$\begin{array}{c}2 \text { группа } \\
(\mathrm{n}=19)\end{array}$} & \multicolumn{2}{|c|}{$\begin{array}{c}3 \text { группа } \\
(\mathrm{n}=34)\end{array}$} & \multicolumn{2}{|c|}{$\begin{array}{c}4 \text { группа } \\
(n=13)\end{array}$} \\
\hline & $\begin{array}{c}\text { абс. } \\
\text { число }\end{array}$ & $\%$ & $\begin{array}{c}\text { абс. } \\
\text { число }\end{array}$ & $\%$ & $\begin{array}{c}\text { абс. } \\
\text { число }\end{array}$ & $\%$ & $\begin{array}{c}\text { абс. } \\
\text { число }\end{array}$ & $\%$ \\
\hline \multicolumn{9}{|c|}{ Локализация язвы } \\
\hline Желудка & 20 & 38 & 7 & 37 & 19 & 56 & 5 & 38 \\
\hline Двенадцатиперстной кишки & 32 & 62 & 12 & 63 & 15 & 44 & 8 & 62 \\
\hline \multicolumn{9}{|c|}{ Возраст, годы } \\
\hline $20-29$ & 20 & 38 & - & & - & & - & \\
\hline $30-39$ & 24 & 46 & - & & 27 & 79 & - & \\
\hline $40-49$ & 1 & 2 & - & & 6 & 18 & 8 & 62 \\
\hline $50-59$ & 6 & 12 & 10 & 53 & - & & 5 & 38 \\
\hline $60-69$ & 1 & 2 & 8 & 42 & 1 & 3 & - & \\
\hline 70 и старше & - & & 1 & 5 & - & & - & \\
\hline \multicolumn{9}{|c|}{ Пол } \\
\hline Мужской & 46 & 88 & 15 & 79 & 32 & 94 & 13 & 100 \\
\hline Женский & 6 & 12 & 4 & 21 & 2 & 6 & - & \\
\hline \multicolumn{9}{|c|}{ Время от момента появления первых симптомов до госпитализации } \\
\hline До 6 часов & 26 & 50 & 8 & 42 & 24 & 71 & 10 & 77 \\
\hline От 6 до 12 часов & 14 & 27 & - & & 10 & 29 & 3 & 23 \\
\hline От 12 до 24 часов & 12 & 23 & 9 & 47 & - & & - & \\
\hline Свыше 24 часов & - & & 2 & 11 & - & & - & \\
\hline \multicolumn{9}{|c|}{ Сопутствующие заболевания } \\
\hline $\begin{array}{l}\text { Стенокардия ФК ІІ-ІІІ, постинфарктный } \\
\text { кардиосклероз, сердечная недостаточность II Б- } \\
\text { III ст. }\end{array}$ & 7 & 13 & 12 & 63 & - & & - & \\
\hline Артериальная гипертензия III ст. & 3 & 6 & 5 & 26 & - & & - & \\
\hline Артроз крупных суставов & - & & 3 & 16 & 1 & 3 & 2 & 15 \\
\hline Сахарный диабет & 4 & 8 & 2 & 11 & - & & - & \\
\hline Хроническая обструктивная болезнь легких & - & & 2 & 11 & - & & - & \\
\hline \multicolumn{9}{|c|}{ Характер перитонита } \\
\hline Серозный & 23 & 44 & 6 & 32 & 13 & 38 & 6 & 48 \\
\hline Серозно-фибринозный & 29 & 56 & 11 & 58 & 21 & 62 & 7 & 52 \\
\hline Гнойный & - & & 2 & 10 & - & & - & \\
\hline \multicolumn{9}{|c|}{ Распространенность перитонита } \\
\hline Местный & 17 & 33 & 1 & 7 & 24 & 71 & 7 & 55 \\
\hline Диффузный & 12 & 23 & 4 & 21 & 7 & 20 & 4 & 30 \\
\hline Распространенный & 23 & 44 & 14 & 72 & 3 & 9 & 2 & 15 \\
\hline
\end{tabular}

Качество жизни больных представлено в таблице 2.

Качество жизни в группе больных после иссечения прободной язвы выше, чем в группе пациентов после ушивания прободной язвы, по всем шкалам. При этом достоверно снижены показатели качества жизни у больных, перенесших ушивание язвы, по шкалам «физическая функция», «физическая роль», «физическая боль», «физический компонент здоровья» по сравнению с таковыми у пациентов после иссечения язвы. Показатели качества жизни пациентов после иссечения язвы выше, чем после резекции желудка по Бильрот-I. При этом достоверно снижены показатели качества жизни у больных после резекции желудка по Бильрот-I по шкалам «физическая функция», «физическая роль», «физическая боль», «психическое здоровье». Однако значения интегральных показателей не являются статистически достоверными. Качество жизни больных после резекции желудка по Бильрот-II достоверно ниже, чем в группе пациентов после иссечения прободной язвы, по всем шкалам. При сравнении показателей качества жизни больных в группах после ушивания прободной язвы и после резекции желудка по Бильрот-I статистически достоверных различий не зафиксировано. 
Таблица 2

Сравнение показателей качества жизни пациентов после различных способов хирургического лечения прободной язвы

\begin{tabular}{|l|c|c|c|c|}
\hline \multicolumn{1}{|c|}{ Шкалы SF-36 } & 1 группа $(\mathrm{n}=52)$ & 2 группа $(\mathrm{n}=19)$ & 3 группа $(\mathrm{n}=34)$ & 4 группа $(\mathrm{n}=13)$ \\
\hline Физическая функция & $88,2 \pm 1,2^{2,3,4}$ & $60,3 \pm 8,7^{1}$ & $56,2 \pm 2,5^{1}$ & $47,9 \pm 3,9^{1}$ \\
\hline Физическая роль & $80,3 \pm 3,9^{2,3,4}$ & $46,2 \pm 6,9^{1}$ & $44,1 \pm 4,6^{1}$ & $42,2 \pm 3,2^{1}$ \\
\hline Физическая боль & $76,7 \pm 1,6^{1,3,4}$ & $59,2 \pm 7,9^{1,4}$ & $49,8 \pm 2,3^{1,4}$ & $34,9 \pm 2,0^{1,2,3}$ \\
\hline Общее здоровье & $65,9 \pm 2,2^{4}$ & $61,8 \pm 6,1^{4}$ & $57,7 \pm 3,4^{4}$ & $32,2 \pm 3,1^{1,2,3}$ \\
\hline Жизнеспособность & $56,2 \pm 1,2^{4}$ & $54,8 \pm 4,2^{4}$ & $56,1 \pm 1,8^{4}$ & $30,8 \pm 1,5^{1,2,3}$ \\
\hline Социальная функция & $74,7 \pm 3,2^{4}$ & $64,9 \pm 8,7^{4}$ & $63,4 \pm 5,1^{4}$ & $36,7 \pm 4,9^{1,2,3}$ \\
\hline Психическое здоровье & $59,7 \pm 2,3^{3,4}$ & $53,8 \pm 3,1^{4}$ & $43,1 \pm 4,5^{1}$ & $36,9 \pm 2,1^{1,2}$ \\
\hline Эмоциональная роль & $52,9 \pm 4,9^{4}$ & $47,2 \pm 10,5$ & $45,0 \pm 6,9$ & $32,8 \pm 5,9^{1}$ \\
\hline Физический компонент здоровья & $54,5 \pm 1,4^{2,4}$ & $43,2 \pm 5,3^{1}$ & $47,8 \pm 3,9^{4}$ & $37,8 \pm 2,9^{1,3}$ \\
\hline Психический компонент здоровья & $47,7 \pm 1,9^{4}$ & $40,3 \pm 2,6$ & $41,1 \pm 2,8$ & $31,7 \pm 3,6^{1}$ \\
\hline
\end{tabular}

Примечание: ${ }^{1-4}$ - достоверные различия $(\mathrm{p}<0,05)$ показателей относительно соответствующей группы пациентов.

Таблица 3

Оценка результатов хирургического лечения прободной язвы желудка и ДПК по модифицированной шкале Visick

\begin{tabular}{|l|c|c|c|c|c|c|c|c|}
\hline \multirow{2}{*}{ Результаты лечения } & \multicolumn{2}{|c|}{ 1 группа $(\mathrm{n}=52)$} & \multicolumn{2}{c|}{2 группа $(\mathrm{n}=19)$} & \multicolumn{2}{c|}{3 группа $(\mathrm{n}=34)$} & \multicolumn{2}{c|}{4 группа $(\mathrm{n}=13)$} \\
\cline { 2 - 11 } & Абс. число & Аб. & Аб. число & $\%$ & Абс. число & $\%$ & Абс. число & $\%$ \\
\hline Отлично & 18 & 35 & 2 & 11 & 8 & 24 & - & \\
\hline Хорошо & 23 & 44 & 6 & 32 & 14 & 41 & 3 & 23 \\
\hline Удовлетворительно & 11 & 21 & 9 & 47 & 12 & 35 & 8 & 62 \\
\hline Неудовлетворительно & - & & 2 & 10 & - & & 2 & 15 \\
\hline
\end{tabular}

Качество жизни больных после ушивания прободной язвы выше, чем в группе пациентов после резекции желудка по Бильрот-II, по всем шкалам. При этом достоверно снижены показатели качества жизни у больных после резекции желудка по Бильрот-II по шкалам «физическая боль», «общее здоровье», «жизнеспособность», «социальная функция», «психическое здоровье». Показатели качества жизни больных в группе после резекции желудка по Бильрот-I выше, чем в группе после резекции желудка по Бильрот-II, по всем шкалам. При этом статистически достоверными являются различия показателей по шкалам «физическая боль», «общее здоровье», «жизнеспособность», «социальная функция», «физический компонент здоровья».

Оценка результатов хирургического лечения представлена в таблице 3.

Анализ результатов хирургического лечения пациентов с язвенной болезнью желудка и ДПК, осложненной перфорацией, по модифицированной шкале Visick показал, что наибольшее количество отличных и хороших результатов выявлено у пациентов после иссечения язвы, соответственно $35 \%$ и $44 \%$. В группе больных после резекции желудка по Бильрот-II отличных результатов не зафиксировано. Неудовлетворительные результаты лечения получены у $10 \%$ больных после ушивания язвы и у $15 \%$ пациентов после ре- зекции желудка по Бильрот-II. В группах больных после иссечения язвы и после резекции желудка по Бильрот-I неудовлетворительных результатов не зафиксировано (таблица 3). У 2 пациентов после ушивания прободной язвы были эпизоды язвенного кровотечения. Больные проходили курс консервативной терапии, от оперативного лечения отказались. В настоящее время больных беспокоят частые боли в эпигастрии, чувство тяжести в левом подреберье, снизилась их трудоспособность. У 2 больных после резекции желудка по Бильрот-II выявлен демпинг-синдром средней степени тяжести. Пациентам проводился курс консервативной терапии в условиях стационара. В настоящее время больных беспокоят частые болевые приступы, общая слабость, вздутие живота, поносы. Их трудоспособность снижена.

Таким образом, наилучшим качеством жизни обладают больные, перенесшие операцию иссечения язвы, которая должна являться способом выбора лечения перфоративных язв желудка и двенадцатиперстной кишки. На втором месте по влиянию на качество жизни находится резекция желудка по модификации Бильрот-I. Наихудшие отдаленные результаты получены при ушивании язвы и резекции желудка по модификации Бильрот-II. Разработанный в нашей клинике закрытый способ иссечения язв не требует высокой квалификации хирургической бригады, позволяет су- 
щественно снизить продолжительность операции и риск гнойно-септических осложнений.

\section{ЛИТЕРАТУРА}

1. Афендулов С.А., Журавлев Г.Ю., Краснолуцкий Н.А. Лечение прободной язвы. - М. : Медицина, 2005. - $166 \mathrm{c}$.

2. Василенко В.Х., Гребенев А.Л. Болезни желудка и двенадцатиперстной кишки. - М. : Медицина, 2016. - 344 c.

3. Ермолов А.С., Смоляр А.Н., Шляховский И.А. 20 лет неотложной хирургии органов брюшной полости в Москве // Хирургия. Журнал им. Н.И. Пирогова. - 2014. - № 5. - С. 7-16.

4. Лазаренко В.А., Суковатых Б.С., Антонов А.Е., Новомлинеи Ю.П. Анализ факторов риска развития язвенной болезни в сравнении с другими заболеваниями гепатопанкреатодуоденальной зоны // Курский научно-практический вестник «Человек и его здоровье». - 2009. - № 1. - С. 95-100.
5. Лазаренко В.А., Антонов А.Е. Роль социальных факторов риска в развитии язвенной болезни в Курской области // Курский научно-практический вестник «Человек и его здоровье». - 2016. - № 2. С. 35-39.

6. Тагиров М.Р., Халилов Х.М., Закиров А.М., Шакиров М.И. Варианты лапароскопического лечения перфоративных дуоденальных язв // Вестник современной клинической медицины. 2013. - T. 6, № 5. - C. 158-161.

7. Søreide K., Thorsen K., Søreide J.A. Strategies to improve the outcome of emergency surgery for perforated peptic ulcer // Br J Surg. - 2014. - Vol. 101, N 1. P. e51-64. - doi: 10.1002/bjs.9368.

8. Lau J.Y., Sung J., Hill C., Henderson C., Howden C.W., Metz D.C. Systematic Review of the Epidemiology of Complicated Peptic Ulcer Disease: Incidence, Recurrence, Risk Factors and Mortality // Digestion. - 2011. - Vol. 84, N 2. - P. 102-113. - doi: 10.1159/000323958. 